\title{
MODOS DE SUBJETIVAÇÃO NO SISTEMA AVALIATIVO DA PÓS-GRADUAÇÃO: CONHECER, ESTRANHAR, INTERROGAR
}

\author{
Subjectivation Modes in the Evaluative System of the Graduate: To Know, to Wonder, to \\ Interrogate
}
Modos de Subjetivación en el Sistema Evaluativo del Post-grado: Conocer, Sorprenderse, Interrogar

\author{
Modes de Subjectivation dans le Système D'évaluation du Troisième Cycle: Connaître, \\ Trouver Étrange, Interroger
}

Janaína Rodrigues Geraldini

Bolsista de Pós-Doutorado (PNPD/CAPES) do Programa de Pós-Graduação em Psicologia Social e docente externa do Departamento de Psicologia da Universidade Federal de Sergipe (UFS). Doutora em Psicologia pela Universidade Federal do Rio de Janeiro (UFRJ). Mestra em Psicologia pela Universidade Federal de Santa Catarina (UFSC).

Pedro Paulo Gastalho de Bicalho Professor do Instituto de Psicologia e do Programa de Pós-Graduação em Psicologia da Universidade Federal do Rio de Janeiro (UFRJ). Mestre e Doutor em Psicologia pela Universidade Federal do Rio de Janeiro (UFRJ). Bolsista de Produtividade em Pesquisa (CNPq) e Jovem Cientista (FAPERJ).

Recebido em: 06/08/2015 / Revisado em: 26/10/2015 / Aceito em: 30/01/2016

Resumo

A proposta deste artigo é propor uma reflexão sobre os modos de subjetivação produzidos pelo sistema avaliativo nos programas de pósgraduação em psicologia. De que maneira nos reconhecemos nessa e diante dessa tecnologia? Quais são os modos de tensionarmos e configurarmos suas forças atuantes? Como nos produzimos e nos estetizamos nesse cenário? Tais questionamentos nos levam à construção de seis camadas, quais sejam: problema contemporâneo; controle e regulação; produtividade; individualização e competitividade; exclusão e hierarquia; outros modos de se reconhecer, constituir e estetizar. Convidamos o leitor a encontrar brechas e possibilidades de escapar aos funcionamentos mais nocivos do sistema avaliativo, bem como encontrar nele mesmo modos de transformá-lo em outras potencialidades.

Palavras-chave: modos de subjetivação; avaliação; pós-graduação; psicologia.

Abstract

The purpose of this article is to propose reflection on the modes of subjectivation produced by the evaluative system in postgraduate programs in psychology. In what way do we recognize ourselves in this technology? What are the ways to stress and configure their acting forces? How do we produce and aesthetize ourselves in this scenario? Such questions lead us to the construction of six layers, namely: contemporary problem; control and regulation; productivity; Individualization and competitiveness; exclusion and hierarchy; other ways of recognizing, constituting and aestheticizing. We invite the reader to find gaps and possibilities to escape from the most harmful functions of the evaluative system, as well as find in itself ways of transforming it into other potentialities.

Keywords: Modes of subjectivation; evaluation; postgraduate studies; psychology. 


\section{Resumen}

Este trabajo tiene el objetivo de proponer reflexiones sobre los modos de subjetivación producidos por el sistema evaluativo en los programas de post- grado en psicología. ¿De qué manera nos reconocemos ante y en esta tecnología? ¿Cuáles son los modos de tensar y configurar sus fuerzas actuantes? ¿Cómo nos producimos y nos estetizamos en esta escena? Estos cuestionamientos nos llevan a la construcción de seis capas: problema contemporáneo; control y regulación; productividad; individualización y competitividad; exclusión e jerarquía; otros modos de reconocerse, construir y estetizar. Invitamos el lector a encontrar huecos y posibilidades de escapar de los funcionamientos más nocivos del sistema evaluativo, como también encontrar en él modos de transformarlo en otras potencialidades.

Palabras clave: modos de subjetivación; evaluación; post- grado; psicología.

\section{Résumé}

Le but de cet article est de proposer une réflexion sur les modes de subjectivation produites par le système d'évaluation sur les programmes de troisième cycle en psychologie. Comment nous pouvons nous reconnaître avantet dans cette technologie? Quels sont les modes de contracter et configurer ses forces d'éxecution? Comment nous nous produisons et nous nous esthétisons dans ce scénario? Ces questions conduisent à la construction de six niveaux, qui sont: problème contemporain; contrôle et réglage; productivité; individualisation et compétitivité; exclusion et hiérarchie; autres façons de se reconnaître, établir et esthétiser. Nous invitons le lecteur à trouver des lacunes et des possibilités d'échapper aux mécanismes les plus nocifs du système d'évaluation, aussi bien que trouver des moyens de le transformer en d'autres potentialités.

Mots-clés: modes de subjectivation; évaluation; troisième cycle; psychologie.

A Coordenação de Aperfeiçoamento de Pessoal de Nível Superior (CAPES) é responsável pelo monitoramento do Sistema Nacional de Pós-Graduação, desde 1976. Trata-se de um órgão vinculado ao Ministério da Educação que, excetuando-se o papel de alguns outros setores no fomento e o papel do Conselho Nacional de Educação na formulação legislativa e na homologação das decisões sobre avaliação, concentra a responsabilidade pelo acompanhamento e avaliação da pós-graduação stricto sensu em uma única agência governamental (Yamamoto, 2004).

Medir a qualidade dos programas nacionais de pós-graduação, com a proposta de acompanhar seu desenvolvimento, vincula-se à realização de avaliações periódicas por meio da coleta de informações, inaugurando um grande sistema de monitoramento que, atualmente, é responsável pelo credenciamento, financiamento e regulamentação desses programas. Tal sistema de avaliação expandiu-se ao longo dos anos, sofreu diferentes propostas e modificações, produziu controvérsias e efeitos entre aqueles que são atravessados pela pós-graduação no país e, com a proposta de busca pela qualidade, desenvolveu técnicas e estratégias, apresentando-se como um sistema em movimento e de grande complexidade.

Atualmente, o dispositivo de avaliação envolve a produção de diferentes saberes e práticas, todos minuciosamente definidos, esquematizados e alocados em conformidades. A composição do processo avaliativo é realizada pela coleta de variadas informações acerca de um programa, pela distribuição dessas informações com o preenchimento de diferentes tipos de relatórios, pela disposição conferida a tais dados a partir de documentos de referências, pela transformação dos dados informados em tabelas, planilhas, conceitos e, finalmente, notas. Aqueles que estão, das mais diversas maneiras, envolvidos nessa composição apontam que o trabalho despendido é grande e que envolve significativa demanda de tempo e esforço. Entendemos que alguns, se não muitos deles, subjetivam a avaliação como uma técnica de punição cujas imposições, de acordo com Foucault (1977-78/2008), não estão restritas a multas e enforcamentos, mas a uma série de exercícios, de trabalhos de moralizações e de correções, que emergem como efeitos das avaliações e que se traduzem como regras que passam a gerir os programas de pós-graduação e, consequentemente, os pesquisadores.

A proposta deste artigo é pensar sobre questões pertinentes aos modos de subjetivação produzidos pelo sistema avaliativo nos programas de pós-graduação em psicologia. Elegemos, então, trazer algumas formações discursivas que aparecem em artigos, em apresentações em eventos e boletins informativos, todos produzidos por docentes e discentes de programas de pós-graduação em psicologia entre os anos de 2008 e 2013, período em que ocorreu a coleta de dados para a pesquisa. Por outro lado, trazemos também artigos publicados na revista Psicologia \& Sociedade no ano de 2004, visto que se trata de uma edição especial voltada para a temática da avaliação e do processo de trabalho nas universidades.

Podemos entender a subjetivação como produzida, em grande parte, por técnicas de punição. Entretanto, é importante escavar outras camadas, a fim de aprofundar como é produzido o dispositivo de avaliação, a partir das contribuições de 
Deleuze (1990). O autor aponta que, na composição de um dispositivo, a dimensão da subjetividade diz respeito aos efeitos provocados pelas articulações entre as linhas de saber e de poder. Nesse sentido, as linhas de subjetivação configuram-se como dispositivos móveis; linhas de fuga que escapam às forças de poder e aos saberes estabelecidos ao formarem regras com características facultativas para a construção de si mesmo. Embora possam escapar às linhas discursivas e de poder, as linhas de subjetivação viabilizam a formação de outros saberes e de outros poderes, movimentando também a maquinaria do dispositivo. Um dispositivo chega ao seu limite extremo quando as linhas de subjetivação são rompidas. Essas linhas de fratura que permitem a passagem de um dispositivo a outro.

Com a proposta de pensar sobre os modos de subjetivação produzidos pelo sistema avaliativo nos programas de pósgraduação em psicologia, perguntamos, então, quais são os modos de se reconhecer nessa e diante dessa tecnologia; como as forças que atuam nesses sujeitos são por eles tensionadas e configuradas; quais são os modos de se produzirem e de se estetizarem. Diante da proposta e da produção de dados deste trabalho, foram construídas seis camadas que dizem respeito aos modos de subjetivação: problema contemporâneo; controle e regulação; produtividade; individualização e competitividade; exclusão e hierarquia; outros modos de se reconhecer, constituir e estetizar.

\section{Problema Contemporâneo}

Apresentamos como "problema moderno" a gestão da universidade, no Brasil e em diversos países, cada vez mais próxima da gestão de uma empresa, junto à gradativa desresponsabilização do Estado no que se refere à qualidade e ao financiamento (Mancebo, 2009). Nas discussões sobre a política de avaliação dos programas nacionais de pós-graduação trazidas em Maraschin e Sato (2013), o gerencialismo crescente na condução das universidades também é apontado, dessa vez como resultado da presença da "cultura de auditoria" na sociedade contemporânea, a qual está implicada, na maioria das profissões, com a preocupação cada vez maior com a garantia da qualidade, e com o incentivo para as pessoas medirem a si próprias e suas qualidades pessoais.

Ainda com relação ao contexto geral universitário, Yamamoto, Tourinho, Bastos e Menandro (2012) consideram que a qualificação da produção estende-se aos limites da avaliação da CAPES, visto que é elemento presente nos próprios mecanismos internos de avaliação das instituições de ensino superior. A avaliação dos programas de pós-graduação é também encontrada ao lado de outras avaliações (de revistas, de professores e de cursos de graduação), na ideia de que o sistema universitário, em diversos aspectos, é avaliado continuamente.

A expressão mais requintada dessa panóplia avaliativa incide sobre a Coordenação de Aperfeiçoamento de Pessoal de Nível Superior [...] e a avaliação que faz da pós-graduação no Brasil. A CAPES, outrora, desempenhara um papel relevante na organização do sistema de pós-graduação brasileiro, mas acabou por incorporar, difundir e aprofundar a mesma lógica produtivista, pragmática e utilitarista. (Mancebo, 2009, p. 13)

Acerca da presença de modos de funcionamento da avaliação dos programas de pós-graduação compreendidos como parte de um conjunto ampliado, que abrange outros contextos cotidianos, encontramos, por fim, em Kastrup (2010, p. 177), que a "dispersão no mar das multitarefas", conectada com a experiência do tempo e a sensação de débito: a dispersão, que solicita velocidade rápida e incompatível com o tempo da pesquisa e da produção do conhecimento, é um funcionamento característico da subjetividade contemporânea. Nessa experiência com o tempo, aparece o sentimento de atraso, de dívida crônica, mesmo quando o ritmo é de perpétua ocupação, de corrida atrás dos prazos e de trabalho ininterrupto.

\section{Controle e Regulação}

Na sociedade de segurança, estudada por Foucault (1970-82/1997, 1976/2005a, 1975/2005b), o controle opera tanto nos corpos individuais (com movimentos atualizados da sociedade disciplinar), como nos corpos coletivos (com movimentos atualizados da sociedade de vigilância). Na sociedade de controle, trabalhada por Deleuze (1992), as relações de forças atravessam o cotidiano de maneira contínua, sem se fixarem em instituições específicas. O controle acontece, assim, a céu aberto, porque vem de todos os lugares e de nenhum lugar em específico. Com relação à regulação, é um modo de funcionamento da sociedade de segurança, trabalhada por Foucault (1977-78/2008), que diz respeito ao processo de normalização, ou seja, ao "jogar e fazer jogar" diferentes distribuições de normalidade, relacionando umas às outras, sem proibições ou prescrições, mas mantendo certo distanciamento, a fim de apreender o ponto no qual as coisas irão se produzir e, com apoio nesse ponto, fazer seus elementos atuarem uns em relação aos outros. 
De maneira mais direta à avaliação dos programas de pós-graduação, Molon (2004) afirma que ela é um dos instrumentos de regulação social do Estado, e Axt (2004) aponta para os modelos de avaliação da pós-graduação como um dispositivo de subjetivação do pesquisador e da formação em pesquisa, como um dispositivo, enfim, que produz modos de ser pesquisador. Nessa mesma linha, Rocha e Rocha (2004) consideram que a avaliação interfere no funcionamento institucional e no autocontrole das ações dos docentes, sendo coercitiva por manter uma regularidade no ritmo de produção sob pena de punição, e sendo critério regulador de práticas, de controle e disciplinamento. Ao lado dessas configurações, trazemos a inquietação de Ferreira (2011, s/p): "É por meio deste sistema de competição regulada que queremos organizar nossa carreira?".

Configurações de regulação e de controle, tecidas em meio a imposições e exigências, produzem inquietações. Mas, por vezes, elas aparecem esvaziadas de condições de ruptura, tal como podemos perceber nas seguintes discussões:

"A CAPES somos todos nós" age como instrumento de controle sobre os pesquisadores que a compõem, de cujas amarras eles não conseguem escapar e, com isso, revela que todos somos partícipes do processo, seja de um modo mais ou menos ativo [...] É importante ter em conta que a frase "a CAPES somos nós" pode funcionar como controle ideológico, escamoteando diferenças entre pesquisadores, PPGs [programas de pós-graduação], CAPES e sociedade, dando-nos a ilusão de que temos condições de interferir e determinar a política de avaliação, o que é bastante questionável. (Maraschin \& Sato, 2013, pp. 2 e 4)

\section{Produtividade}

De acordo com a CAPES (2013), a produção bibliográfica permite a articulação de grupos de pesquisadores e a construção de redes e parcerias entre docentes e programas de pós-graduação. Com isso, queremos apontar para a visibilidade que ganha, em diversos aspectos do cotidiano acadêmico, o quesito de avaliação "produção bibliográfica". Ele movimenta discursos que, muitas vezes, irrompem em visibilidades outras, formam novas parcerias e produzem linhas atravessadas pela questão do chamado "produtivismo". De acordo com Alcadipiani (2011),

chamamos de produtivismo uma ênfase exacerbada na produção de uma grande quantidade de algo que possui pouca substância, o foco em se fazer o máximo de uma coisa 'enlatada', com pouco conteúdo e consequente valorização da quantidade como se fosse qualidade. (p. 1174)

A inserção do quesito produção intelectual na avaliação da CAPES "[...] tem provocado reações de professores e alunos, que questionam o que se tem chamado de "produtivismo acadêmico' [...]" (Aragão \& Cruz, 2010, p. 2); e, conforme podemos perceber no seguinte relato de participação num evento promovido pela Associação Nacional de Pesquisa e PósGraduação em Psicologia (ANPEPP), em 2010:

No debate aberto, uma professora sublinha que perdemos muito tempo reclamando do produtivismo e que o problema mais estressante é a burocracia. [Outro professor] pontua que produzir faz parte do pesquisar e que a questão deve ser com a qualidade. Como avaliar a qualidade e não só a quantidade? Questões complexas e polêmicas foram despertadas incitando a reflexão e o diálogo. (Pozzana, 2010, p. 2)

Diante da atualidade e recorrência, podemos pensar acerca dos modos de subjetivação produzidos no cenário da pósgraduação em psicologia. Inicialmente, é possível percebermos que há controvérsias nas e diante das críticas construídas acerca da produtividade, não refletindo em modos únicos de subjetivação dos envolvidos com essa pós-graduação e com sua produção do conhecimento.

Eles se reconhecem, por um lado, em meio a aspectos considerados importantes e necessários ao seu trabalho, os quais que são proporcionados pela publicização de suas pesquisas, tais como: coletivização de resultados; difusão de ideias; propagação de abordagens teóricas e metodológicas; aparecimento de problemas emergentes e que exigem ampliação das investigações e dos esforços para soluções (Kastrup, 2010); e como compromisso social do pesquisador, validação da qualidade pela apreciação dos pares e responsabilidade dos pesquisadores para com os fundos públicos (Yamamoto et al., 2012). Por outro lado, entendemos que os docentes e pesquisadores de psicologia reconhecem-se em meio a imposições e exigências que são tensionadas pela produção cada vez maior de resultados numéricos (Arantes, 2008; Ferreira, 2011; Guedes, 2011; Kastrup, 2010; Mancebo, 2009; Maraschin \& Sato, 2013; Rocha \& Rocha, 2004; Simões, 2004; Yamamoto et al., 2012; Zanella, 2004) que deve, ainda, ser realizada com apresentação de novos produtos, com parcerias diversificadas 
e em periódicos científicos específicos - essas discussões estão presentes em Zanella (2004) e Kastrup (2010).

Como consequência desses modos imperativos de produção do conhecimento, aparecem artigos inacabados, conclusões pouco amadurecidas (Kastrup, 2010) e resultados espalhados em várias publicações (Kastrup, 2010; Maraschin \& Sato, 2013; Yamamoto et al., 2012). Com isso, os pesquisadores podem se reconhecer e serem reconhecidos como operantes do esvaziamento de sentido, da relevância e da ética em suas pesquisas e publicações, quando estão direcionadas ao alcançar de metas, conforme podemos analisar a partir das formações discursivas que constam em Axt (2004), Rocha e Rocha (2004), Zanella (2004), Mancebo (2009) e Kastrup (2010).

Nos modos em que o produtivismo é subjetivado, encontramos também interligações desse com as tensões promovidas pelo crescente volume de outros encargos presentes na vida acadêmica, conforme pode ser consultado em Kastrup (2010), Axt (2004), Barros (2004), Rocha e Rocha (2004), Mancebo (2009), Castro (2010) e Yamamoto et al. (2012), e pelo cotidiano dos atores, que é reduzido à contabilização de produtos e ao ranqueamento, no qual se destacam aqueles que mais publicam, mais orientam e são mais citados (Rocha \& Rocha, 2004).

Em conjunto com essas questões que envolvem o produtivismo, encontramos, algumas linhas de tensionamento com a temporalidade nas imbricações dos modos de subjetivação de pesquisadores e docentes. No tensionamento, o cotidiano é apressado (Arantes, 2008) e é correria contra o tempo (Kastrup, 2010). Ele também é localizado para além do contexto acadêmico brasileiro (Kastrup, 2010; Yamamoto et al., 2012), em que "tudo é a curto prazo", o que aumenta a velocidade e a superficialidade das informações (Yamamoto et al., 2012).

Ao lado da superficialidade, encontramos a característica contemporânea da "temporalidade acelerada", contrastada com a "temporalidade lenta", que não tem os objetivos da escrita e da produção bibliográfica, e que é lembrada com nostalgia, ao se pensar sobre o "grupo de estudos" que perdeu espaço para o "grupo de pesquisa" (Kastrup, 2010). Ainda nas linhas de tensionamento com a temporalidade, encontramos que objetivos fundamentais na produção do conhecimento, como qualidade e inovação científica, ficam difíceis de serem alcançados, uma vez que existe a "multitemporalidade", na qual colidem diversas velocidades (Kastrup, 2010).

Percebemos também que as relações de forças que tecem o sistema avaliativo nas questões ligadas à produção intelectual formam tensionamentos no cotidiano dos pesquisadores e docentes, e implicam na forte configuração do embate entre quantidade e qualidade. São recorrentes os enunciados que trazem a ideia de "pressão por produção quantificável", tal como podemos ver, por exemplo, em Molon (2004), que afirma que as atuais políticas de avaliação estão centralizadas nos resultados, objetivam medi-los e estabelecer rankings; e também em Rocha e Rocha (2004), que apontam que, sob o foco da produtividade, há a execução de tarefas para se elevar a quantidade de mercadorias produzidas.

A coordenação de psicologia da CAPES instituiu a tabela de melhor produção, em 2007, no intuito de romper com a quantificação ilimitada de produtos bibliográficos e de dar ênfase na qualidade: a adoção da tabela de melhor produção, em conjunto com a adoção do Qualis (de livros e periódicos), caminham na direção de “[...] uma política concreta de avaliação na contramão da multiplicação artificial dos números de produção e, desse modo, contrariam claramente a chamada 'lógica produtivista"” (Yamamoto et al., 2012, p. 746).

Menções sobre tal tabela constam em alguns artigos analisados, bem como a inclusão do quesito "inserção social", entendida como movimento que prioriza avaliar outras questões de produção acadêmica para além da produção bibliográfica (Kastrup, 2010). Mas essa prática de um limite estipulado não esvaziou a agitação dos enunciados que colocam "quanti" versus "quali", pois o produtivismo foi freado pela avaliação em psicologia, "no entanto, [é] apenas um paliativo para uma decisão descolada da realidade do pesquisar" (Guedes, 2011, p. 392); em que aumenta-se a quantidade e diminui-se a qualidade (Maraschin \& Sato, 2013); a pressão pela quantidade da produção promove distorções, como o fracionamento de trabalhos, a redundância de produtos, a multiplicação de produções, sem contribuir com relevância científica ou social (Yamamoto et al., 2012); o "ser melhor nas avaliações" é atrelado ao cumprimento de regras e formatos que nada têm a ver com a qualidade (Arantes, 2008); tudo é contado e pontuado (Arantes, 2008); a avaliação CAPES pressiona professores e alunos de pós-graduação para publicação "quantificável" (Guedes, 2011); impõe-se o problema da quantidade versus qualidade (Guedes, 2011); há baixa qualidade nas publicações (Maraschin \& Sato, 2013) e atulhamento dos processos editoriais (Hutz, Rocha, Spink, \& Menandro, 2010; Maraschin \& Sato, 2013).

\section{Individualização e Competitividade}

A cultura da avaliação na realidade da universidade brasileira está no bojo das políticas neoliberais que se farão sentir a partir da década de 90 do último século, constituindo-se em aprimoramento do racionalismo cientificista consolidado ao longo da era moderna: conhecimento técnico, objetividade, princípios ligados a leis naturais, parâmetros neutros e universais (Rocha 
\& Rocha, 2004, p. 20)

Perguntamos, então, se seriam nas relações de embate entre as pessoas envolvidas com a pós-graduação em psicologia e os referenciais acima apontados (modelo de produção do conhecimento e ameaças à composição da universidade), que se produziriam modos de funcionamento e de inquietações, tais como: a falta de problematização e reflexão; denúncias sistemáticas; e iniciativas cotidianas de combate ao produtivismo, à mercantilização e à cultura individualista (Mancebo, 2009); a presença de pesquisas e reflexões agudas e críticas no meio acadêmico, e da massa de adesão queixosa ao sistema de pós-graduação, mas que não são capazes de fazer uma "reflexão fina e incisiva sobre seus próprios regimes de trabalho" (Ferreira, 2011, s/p); o esvaziamento da discussão coletiva na psicologia, que permanece restrita aos encontros da CAPES com os coordenadores dos programas e aos simpósios da Anpepp (Mancebo, 2009); a dificuldade na produção de um pertencimento coletivo, e oposição e resistência coletiva (Mancebo, 2009).

Nas discussões de Molon (2004) sobre os modelos de produção, aplicação e avaliação do conhecimento para a educação e para os programas de pós-graduação instituídos pela racionalidade hegemônica, encontramos que, dentre as concepções de ciência, há aquela do modelo positivista, que ignora a subjetividade e cujo rigor é fundamentado na aritmética, que, ao quantificar, impõe o etnocentrismo que desqualifica os fenômenos. Para Barros (2004), há uma necessidade de se produzir bifurcações no pensamento hegemônico, visto que esse é compatível com uma racionalidade e uma política que "desprezam os humanos e a vida", quando a universidade brasileira, em suas políticas educacionais de pesquisa e gestão, passa a funcionar com objetivos de cumprimento de metas produtivistas, produzindo perda do conhecimento independente, laico e reflexivo em função da promoção do conhecimento tecnocrático. A tecnocracia, o conhecimento tecnocrático e/ou tecnicismo cientificista também aparecem com funções de incompatibilidade nas discussões trazidas por Coimbra (2004), quando a autora afirma que tal tipo de conhecimento promove o reconhecimento de pesquisas como sendo mais nobres e de maior valor acadêmico do que outras, e por Simões (2004), que aponta para a avaliação da pós-graduação pensada e conduzida pela ótica da tecnocracia, ao invés de pela ótica do educador.

Em Coimbra (2004), também são trazidas reflexões como a comparação do campus universitário como um "pregão", e do professor como um híbrido de cientista e de corretor de valores, visto o funcionamento da universidade como uma empresa capitalista e a necessidade de se preencher relatórios, de alimentar estatísticas, levantar verbas e promover visibilidade para si mesmo e seu departamento. Inflar as estatísticas de "boa gestão dos governos" aparece na discussão sobre políticas científicas (Castro, 2010) em conjunto com a lógica do capital, existente nos produtos e tecnologias demandados pelos governos.

Próximas a essas linhas de discussão, em que aparecem incompatibilidades entre os modos de produção do conhecimento e suas implicações, e entre as ameaças de composição da instituição universitária, encontramos em Arantes et al. (2004), Molon (2004), Rocha e Rocha (2004), Simões (2004), Arantes (2008) e Mancebo (2009) as seguintes discussões: subordinação da produção do conhecimento à lógica do mercado, da demanda de ofertas e de mercado solúvel e descartável; mercantilização e empresariamento da educação superior; gestão da instituição universitária transformada em empresa; valorização da qualidade acadêmica em modelos administrativo-gerenciais e empresarias; ênfase na ordem técnico-gerencial em função do político-pedagógico; existência de imperativos mercantis e intelectuais na produção e contagem de pontos; eficiência da lógica empresarial que remete à pontuação pela capacidade de se desenvolver, ao mesmo tempo, diversas funções e ocupar múltiplos postos; capital, mercado e propriedade priorizados em função do trabalho, da democracia e de direitos sociais; distribuição de recursos marcados pelo colonialismo, pelo viés empresarial e pela ênfase ao modelo científico das ciências duras.

Outras incongruências aparecem em Simões (2004), como o imediatismo da lógica empresarial em contraposição ao "médio e longo prazo" da lógica institucional universitária. Na mesma linha, Kastrup (2004) apresenta a questão dos diferentes ritmos da pesquisa em psicologia, visto sua multiplicidade e sua diversidade teórica e metodológica, que colidem, em termos de ritmo e volume de produção, com a velocidade imposta para a realização do trabalho na academia. Afinado às discussões acima, são marcadas as distâncias entre o regime de tempo do pensamento e a instantaneidade e aceleração nas quais o cotidiano da academia encontra-se submetido. Ainda em Rocha e Rocha (2004), encontramos que a naturalização de efeitos do trabalho acadêmico - como produzido em uma grande empresa prestadora de serviços e com exigência de mercado de trabalho rápido, eficiente e de resultados quantificáveis - deve ser recusada, visto o conhecimento que se detém, nas Ciências Humanas, dos riscos de naturalização dos "objetos" de conhecimento.

No contexto do sistema de pós-graduação dos programas de psicologia destacamos, inicialmente, alguns modos de funcionamento coletivo que entram em confronto com a forte instituição da individualização, sendo por ela esvaziados, dificultados e incapacitados. Nesse cenário, o coletivo é transformado em ameaça e perda de tempo (Rocha \& Rocha, 2004). Tais encontros acontecem quando individualização e competitividade são reconhecidas como efeito dos modos conflitantes de funcionamento, como é possível visualizar nos seguintes textos: o "pesquisador solo" é figura que aparece 
como modo de subjetivação no espaço acadêmico, pela adesão de uma perspectiva individualista de se trabalhar (Castro, 2010); o empreendedorismo conecta-se à competitividade e ao individualismo, quando a primeira é apresentada como uma regra, e o segundo, como valor e prática de base para o padrão que é socializado (Mancebo, 2009); a competição aparece como atuante entre os programas de pós-graduação e os pesquisadores (Maraschin \& Sato, 2013), como estímulo cotidiano (Arantes, 2008; Rocha \& Rocha, 2004) e como lógica excludente (Axt, 2004); o individualismo, junto à competitividade, disciplinarização, homogeneização e exclusão, aparece como lógica de orientação e regulação do modelo avaliativo (Axt, 2004); o isolamento é gerado pela produtividade, competência, autonomia e competitividade, como palavras de ordem no "mercado de saberes" (Rocha \& Rocha, 2004); no processo de avaliação, tangenciado pelas formas de organização do trabalho docente, há a lógica empresarial que produz efeitos: na competitividade, o cotidiano é reduzido à contabilização dos produtos; na individualização das ações (em conjunto com a redução da esfera pública a um jogo de interesses privados) vive-se, de maneira quase exclusiva, em um mundo de administração burocrática do espaço doméstico (Rocha \& Rocha, 2004).

No contexto das políticas científicas, Castro (2010) destaca que a distribuição de recursos instaura a luta de todos contra todos; em Coimbra (2004), encontramos indignações acerca da competição por financiamentos escassos, sucateamento dos programas na área de humanidades e aumento abusivo de obrigações e de intolerâncias burocráticas. Nas discussões feitas pela autora, ainda aparece o aumento das exigências de capacitação docente e a diminuição para suas condições (Coimbra, 2004). Ferreira $(2011, \mathrm{~s} / \mathrm{p})$ discute que "[...] a promessa de recursos e reconhecimento está submetida à entrada em um sistema de competição regulada (e altamente burocratizada no nosso caso) [...]", e que o trabalho investido é muito superior aos recursos distribuídos; Mancebo (2009), por sua vez, considera que está naturalizada a escassez de recursos, tornando-se "competente" aquele que consegue acessá-los.

\section{Exclusão e Hierarquia}

Todos nós sabemos que o grande "frisson" que nos mobiliza a todos e todas não reside em nenhuma avaliação que no âmbito das nossas próprias universidades pode ser levada a cabo, mas no Coleta CAPES, que constitui, quase que exclusivamente, o dispositivo de como e por quem nossas atividades de pós, e também da graduação, são avaliadas, reguladas e parametrizadas (Castro, 2010, p. 624, grifos da autora).

Aqueles que se opõem a tais modos de funcionamento são desqualificados como militantes ou como improdutivos (Mancebo, 2009). Podem ser rejeitados como românticos, aventureiros, incompetentes, "do contra", causadores de embaraço, pois, de um lado, há o risco da inconveniência no espaço público, o ostracismo melancólico e a liberdade do pensamento; de outro lado, há a conformidade com a opinião estabelecida e a adesão aos limites impostos (Castro, 2010). “[...] Estamos todos(as) afetados(as) pela lógica capitalista que define perversamente os excluídos e os incluídos, e vivemos o sofrimento ético-político" (Molon, 2004, p. 119).

A estigmatização, desqualificação e negação são inscrições que também se desenham em meio a outras discussões. Acerca de solicitações às agências de fomento não atendidas, pesquisas e pesquisadores são marcados como pouco qualificados e incompetentes (Coimbra, 2004). Como consequência, a autora aponta para a ausência de determinados temas nos cursos, pesquisas e extensões a partir do momento em que temas colocados como políticos são classificados como nãocientíficos (Coimbra, 2004). Nesse sentido de exclusão, encontramos que algumas atividades são investidas e valorizadas em detrimento de outras (Maraschin, 2004) e que a intolerância à diferença é instituída à medida que se consolida um modelo único e absoluto de leitura do mundo (Arantes et al., 2004).

Nesse movimento de exclusão, a avaliação dos programas de pós-graduação surge, de maneira mais marcada, quando apontado que seu modelo não parece ser capaz de contemplar a diversidade e a heterogeneidade da prática da educação (por isso, ensino e pesquisa deixam de acontecer), e que seus critérios ignoram a especificidade das universidades (Simões, 2004). Ao lado disso, indica-se a possibilidade de desestímulo de iniciativas que demandam maior tempo para resultar em produção qualificada (Maraschin \& Sato, 2013), e aponta-se para a valorização somente de algumas publicações, produzindo a desqualificação de outros tipos de produção e a desvalorização do educador (Arantes, 2008). A nota de avaliação de um programa de pós-graduação é utilizada como selo de qualidade, mas também serve para retirar ou reduzir número de bolsas de estudos, bem como excluir professores dos programas quando há o entendimento de que eles não se conseguem se adequar aos critérios estabelecidos, não têm perfil para a pós-graduação ou, ainda, não são suficientemente produtivos (Guedes, 2011).

Abordando a questão da hierarquização, encontra-se, por um lado, as classificações hierarquizantes de docentes, de 
alunos, revistas e eventos, e a legitimação de uma elite acadêmica (Mancebo, 2009; Rocha \& Rocha, 2004). Nessa mesma linha, aponta-se para a possibilidade de existência de "grupos seletos excelentes" e de "massas de sobrantes", visto os níveis crescentes de exigências para a pesquisa e para o pesquisador e a quantidade "crescente e fabulosa" para aqueles que conseguem cumprir tais exigências (Castro, 2010). Por outro lado, a hierarquização pode aparecer em contexto de provocação:

Melhor avaliados então seriam, os pensadores aqui citados, se tivessem trocado toda esta militância docente, esta vivacidade intelectual ou suas atividades políticas (como às vezes são definidas pejorativamente tais produções), por alguns artigos publicados anualmente em revistas indexadas, de preferência em língua estrangeira [...]. Mas não mereceriam de nós, como têm merecido, todas as homenagens. (Arantes et al., 2004, p. 65)

Diante da composição desse conjunto de enunciados, podemos perceber a característica do conflito cotidiano que atravessa os modos de fazer e de se reconhecer como docentes e pesquisadores dos programas de pós-graduação em psicologia. Os modos como os sujeitos se reconhecem, se produzem e se formam envolve a combinação de suas práticas e saberes com o sistema avaliativo que provoca, muitas vezes, o rompimento com compromissos éticos e estéticos entendidos como parte integrante e necessária do trabalho acadêmico e de pesquisa.

Ao criticar o sistema avaliativo, criticam-se os modos entendidos como compatíveis com suas exigências. Aquele cuja prática descumpre tais exigências é criminalizado ${ }^{1}$ como sujeito que não contribui para seu programa de pós-graduação como um todo. Aparece como um ser que boicota o sistema, mas também com implicações de boicote ao próprio programa no qual atua e aos seus colegas de trabalho e orientandos. Também é criminalizado aquele que prima exclusivamente pela produtividade, sendo colocado como ser vendido e/ou perverso. Tais modos de se reconhecer e ser reconhecido movimentam uma rígida dualidade daqueles a favor e contra o sistema avaliativo, impedindo a formação e visibilidade de outras posturas, fluidas, diferentes. Talvez o maior desafio seja o de se reconhecer como sujeito que é avaliado, portanto implicado no sistema avaliativo, tendo responsabilidades daí decorrentes à medida que governa suas práticas e a construção de conhecimento com base em posturas éticas e estéticas, em que tal implicação não está enraizada em um modo de funcionamento automático e cumpridor de ordens.

\section{Outros Modos de se Reconhecer, Constituir e Estetizar}

Dentre outros tensionamentos que vibram os modos de se reconhecer nessa rede de relações do qual o sistema de avaliação encontra-se envolvido, encontramos dificuldades e angústias (Zanella, 2004); sofrimento, perplexidade, incoerências e injustiças (Castro, 2010); tédio, estresse, segregação e precarização (Rocha \& Rocha, 2004); esgotamento (Hutz et al., 2010); opressão (Arantes et al., 2004); submissão (Ferreira, 2011); autoritarismo (Simões, 2004); rotina insalubre (Kastrup, 2010); estraçalhamento (Axt, 2004), adoecimento e preocupação com a saúde dos profissionais (Aragão \& Cruz, 2010; Maraschin \& Sato, 2013; Rocha \& Rocha, 2004; Yamamoto et al., 2012); desvalorização, autoplágio e fraude (Mancebo, 2009).

Tais tensionamentos são configurados em diferentes modos de produção de si e de mundo. Por vezes, eles aparecem equilibrados ou talvez compensados pelo entendimento da construção de novas possibilidades a partir do sistema de avaliação, por exemplo, trazem os enunciados dessa entrevista:

A avaliação pela CAPES nos mobilizou muitas vezes a realizar um trabalho desgastante e excessivo, mas gerou aspectos positivos na medida em que nos forçou a pensar e repensar a nossa cara, exigiu que construíssemos um mapa detalhado de nossas atividades e realizações. A sua realização coletiva [foram distribuídas tarefas entre os docentes para o preenchimento do coleta] foi importante para repensar o projeto da Pós. Assim, a avaliação trouxe tanto aspectos negativos, que tentamos nos mobilizar para responder, como aspectos positivos [...] No movimento de nos conhecermos melhor, conseguimos identificar nosso perfil [...] Antes o programa já tinha direcionamentos para a internacionalização, convênios com universidades fora do Brasil, mas como se torna parte importante da avaliação da CAPES, devemos dar mais visibilidade a esse aspecto. (Aragão, 2010, p. 3)

\footnotetext{
1 Para Dornelles (1988), a construção de critérios que definem os sujeitos perigosos e as práticas incompatíveis com um grupo social ultrapassa as regras legisladas no código penal acerca do que é crime. Nesse sentido, o autor diferencia "incriminação" (quando o sujeito é submetido à lei oficial) de "criminalização" (quando o sujeito é submetido aos códigos sociais). Ambos os processos movimentam vigilância, punição, controle e estigmatização. Conferir em: Dornelles, J. R. (1988). O que é crime. São Paulo: Brasiliense.
} 
Outras vezes, os tensionamentos tanto produzem rupturas quanto formam acoplamentos e reconhecimentos de si em conjunto com os próprios modos de funcionamento que os produzem, como podemos visualizar a seguir:

[...] a universidade - e quando dizemos universidade, referimo-nos exatamente ao conjunto de atores que nela atua, incluindo docentes em regência de turma, em atividades de pesquisa, em diferentes posições dos quadros administrativos - vem fomentando um diálogo com os representantes das políticas neoliberais no mesmo tom com que estes lhe dirigem a palavra, contribuindo, desse modo, para reafirmar as expectativas de uma lógica de mercado que pretende cristalizar um único modo de ser eficiente e produtivo [...] até que ponto estamos alimentando o que se vem construindo hegemonicamente como sentido de 'excelência', 'produtividade' e 'autonomia'? [...]. (Rocha \& Rocha, 2004, pp. 32-33)

Importante dizer que esses acoplamentos e reconhecimentos aparecem como configurados por meio de constrangimentos normativos que produzem isolamento e individualização: "[somos] mais interessados em estabelecer nossas próprias reputações [...] do que em lutar pela liberdade de pensar"; por meio de conformação: "[...] o momento que vivemos hoje na universidade tem marcado nossa posição coletiva como cada vez mais conformada com aquilo que se espera de nós [...]"; e por meio de aparente impossibilidade de se traçar outros modos de existir: não parece haver possibilidade de existência, como professor e pesquisador, fora desse sistema, "Isso é o que somos levados a crer" - tal discussão encontra-se em Castro (2010, p. 623).

Ao lado desses modos de produção de si e do mundo, os tensionamentos também ganham forma de lutas silenciosas, privatizadas e instantâneas, conforme vemos no seguinte texto que problematiza a construção de políticas científicas para a pós-graduação:

Fazemos disso assunto de reuniões locais a portas fechadas, de alguns manifestos tímidos aqui e ali, de queixumes e choramingos com amigos chegados, enfim, privatizamos aquilo que poderia, e talvez, deveria se publicizar, não apenas no sentido de ganhar visibilidade, mas, basicamente, como uma questão coletiva que suscita litígio, discordância e que, por isso, deveria ser ponto recorrente de discussão pública [...] lamentavelmente, essas indagações se dispersam como sofrimentos individuais coagulados sob forma de inconformismos passageiros, insuficientes para constituir uma força pública, ou contrapública. (Castro, 2010, p. 623)

Os tensionamentos que se formam no contexto do sistema de avaliação da pós-graduação, e que envolvem em seu conjunto problemas conectados ao cotidiano da vida acadêmica, também produzem práticas, propostas e convites a mudanças, mesmo vibrando em tons e frequências de "luta feroz e surda", de "forças de morte contra o sopro da vida" (Barros, 2004) ou, ainda, atravessados por precariedades:

Aos trancos e barrancos, resistindo - nem sempre utilizando as estratégias mais produtivas - denunciando, cansando algumas vezes - indignando-nos - a maior parte do tempo - estamos vivendo os estertores da universidade pública brasileira, em especial na área conhecida como Ciências Humanas e Sociais. (Coimbra, 2004, p. 87)

Deles, são desenhadas outras possibilidades de configurações e novas dimensões de tensionamentos, nas quais os sujeitos envolvidos na pós-graduação de psicologia possam se reconhecer, constituir e estetizar. Junto a essas, outras práticas, propostas e convites são feitos em praticamente todos os textos analisados: Produzir outros referenciais, marcar outros princípios norteadores (como solidariedade e inovação), produzir conhecimentos que modifiquem e revolucionem explicações e modelos estabelecidos e socialmente aceitos, e que sejam marcados pelo compromisso ético, político e estético e com a formação de pesquisadores criativos (Arantes et al., 2004; Axt, 2004; Ferreira, 2011; Machado, 2004; Rocha \& Rocha, 2004; Zanella, 2004); promover explicitação de polêmicas, conflitos e relações de poder que se apresentam no universo acadêmico, com leitura e problematização da realidade e com a análise dos efeitos das próprias práticas (Arantes et al., 2004; Barros, 2004; Castro, 2010; Coimbra, 2004; Rocha \& Rocha, 2004; Zanella, 2004); fazer as diferenças escaparem, e reconhecer o espaço, o outros e a si mesmo nos seus multiversos, nas suas multiplicidades e singularidades (Arantes et al., 2004; Axt, 2004; Barros, 2004; Maraschin, 2004; Rocha \& Rocha, 2004; Simões, 2004; Zanella, 2004); resistir ao não temer desvios, errâncias e "perdas de tempo", e ao promover exercícios de paciência, lentidão, gratuidade e atenção (Arantes, 2008); lutar pela produção de referenciais mais favoráveis ao exercício do pensamento, deslocando as coordenadas de eficiência, produtividade e autonomia, e situando-as em outros registros: a primeira, como compromisso com melhores condições de trabalho e de exercício profissional; a segunda, pela busca de ampliação possível da produção, tendo como foco a garantia da qualidade, e, por fim, a autonomia como construção coletiva, criando sentidos comuns para o fazer por meio 
do exercício ético-político das práticas (Rocha \& Rocha, 2004).

O rompimento com o atual modelo de avaliação aparece de maneira mais pontual nas discussões dos textos que trazem propostas para se pensar outros modos de garantir qualidade, transparência, responsabilidade e prestação de contas do dinheiro público (Maraschin \& Sato, 2013); nas propostas de construção de avaliações que considerem a história de avanços de cada programa na busca de sua própria excelência, e não necessariamente igual a todos os demais, cuja meta não seja a sentença, o veredicto e os rankings, mas a produção dessa mesma excelência com uma política mais justa e mais contribuinte para a pós-graduação e a pesquisa no Brasil (Axt, 2004); na construção de outra política de avaliação, que contemple a diversidade e pluralidade dos conhecimentos produzidos (Molon, 2004); e, ainda, na consideração de índices sem a necessidade de avaliadores (como a participação na administração, graduação e extensão), na invenção de outros modos de lidar com as políticas da pós-graduação na saída do sistema, na criação de sistemas paralelos ou contra-agências de financiamento (Ferreira, 2011).

Encontramos, em outros modos de se reconhecer, construir e estetizar, a convocação de agências como a Associação Nacional de Pesquisa e Pós-Graduação em Psicologia (ANPEPP) e a Sociedade Brasileira de Psicologia (SBP), a fim de promoverem encontros nos quais se possa coletivizar a busca por um novo mundo acadêmico (Guedes, 2011). E a convocação do próprio sistema de avaliação, a fim de: aprimorar procedimentos de monitoramento que sejam mais sensíveis à qualidade do conhecimento produzido (Yamamoto et al., 2012); pensar e debater, constantemente, os critérios usados nas avaliações, bem como discutir sobre critérios mais específicos e que se encaixem melhor na área da psicologia (Aragão \& Cruz, 2010); valorizar o próprio processo de trabalho, e não somente as medidas de desempenho (Maraschin \& Sato, 2013); promover uma construção partilhada, com fundamentos seguros e regras confiáveis para a produção e avaliação, com possibilidades de revisão e com transformação dos modos dominantes do conhecer (Molon, 2004).

Percebemos que, nas inscrições em novos modos de subjetivação, a política encontra-se presente. Apresentamos, por fim, outras inscrições nessa direção, que enfatizam tal relação: ir além da crítica, do lamento, da negação individual e da simplificação da vida profissional, na direção de novas práticas, de territórios arejados e promotores de vida, de pensamento e de coletivos, de espaços de diálogos, aliando-se a movimentos que se espalham pelo mundo a fim de fazer a luta mudar de patamar e de estratégia por meio da criação de novos dispositivos (Coimbra, 2004; Maraschin \& Sato, 2013; Molon, 2004; Rocha \& Rocha, 2004); conjugar, em um só paradigma, as figuras do docente/pesquisador e do militante (Mancebo, 2009).

\section{Considerações e Interrogações}

Que o adversário se apóie em alguma espécie de dominação que você tem sobre ele para tentar derrubá-la e transformá-la em uma dominação que ele teria sobre você constitui, inclusive, a melhor valorização do que está em jogo e resume toda a estratégia de luta: à maneira do judô, a melhor réplica a uma manobra adversária é nunca recuar, mas retomá-la por sua conta, reutilizá-la para sua própria vantagem como ponto de apoio da fase seguinte [...] É a co-ação que me interessa: como ela pesa sobre as consciências e se inscreve no corpo; como ela revolta as pessoas e como elas a ludibriam. É precisamente nesse ponto de contato, de fricção, eventualmente de conflito entre o sistema das regras e o jogo das irregularidades que situo sempre a minha interrogação. (Foucault, 1975/2012, pp. 38-40)

O sistema de avaliação dos programas nacionais de pós-graduação é uma tecnologia complexa, que demanda inúmeros elementos para compreender seu funcionamento. Além disso, encontra-se em constante atualização e atua de maneira incisiva e concreta nos programas nacionais de pós-graduação, justamente por conter, em sua construção, uma multiplicidade de agenciamentos. Essa multiplicidade permite-nos entender que, dentro desse sistema, não cabe apenas avaliar: o dispositivo da avaliação, em muitos aspectos, confunde-se com os próprios programas de pós-graduação.

Se perguntarmos por que o sistema de avaliação demanda incrível e estafante trabalho para aqueles que se encontram nele envolvidos, podemos indicar que é: pela sua centralidade; pelas proporções que ganha o processo avaliativo; pelas inúmeras redes que ali operam; pela proposta de intervenção e gerenciamento do sistema nacional de pós-graduação. Podemos visualizar, enfim, que muito está em jogo quando um sistema propõe-se a modulações de conjunto nas quais todos os programas nacionais devem funcionar em conformidade com demandas e metas. Ao mesmo tempo em que o sistema de avaliação agencia a formação de recursos humanos e materiais, ele também promove que esses recursos sejam desviados das atividades regulares da pós-graduação para sua sustentação e atuação. As relações que envolvem o sistema avaliativo - e nas quais ele se envolve - trazem sobrecarga, regime árduo de trabalho, complexidade, controle minucioso, controvérsias, necessidade de atualizações, erros de percurso, favorecimentos e desfavorecimentos.

O sistema de avaliação, centralizado pela agência CAPES, torna-se, atualmente, um grandioso aparelho de saber dos 
programas nacionais de pós-graduação. As práticas do processo avaliativo estão norteadas, e são sustentadas, por uma composição de diversos documentos que se conectam entre si e que propiciam uma vigilância categorizada e comparativa dos programas. Como efeitos dessa composição, os próprios programas de pós-graduação passam a entender-se como programas a partir do levantamento e organização de dados para o processo avaliativo: para que os programas de pósgraduação compreendam-se como programas devem, antes, entender o sistema que os avalia. Pensando sobre as relações de forças que atravessam a composição do sistema de avaliação, entendemos que suas finalidades, implicações políticas e modos de funcionamento não permitem a existência de um programa de pós-graduação, no Brasil, que desconsidere o modelo arquitetado como indissociável de uma pós-graduação, e passe sem o seu crivo.

O produtivismo é um enunciado recorrente, encontrado em diversos espaços. É criticado por estar aliado à privatização, ao capitalismo, ao modelo empresa e ao neoliberalismo. Tal regularidade, que diz respeito ao vínculo feito entre o sistema de avaliação e um modelo de Estado que coloca em risco a autonomia da universidade e suas características de instituição pública, laica, gratuita, autônoma e de qualidade, nasce no final dos anos de 1990, com referências e críticas baseadas nos problemas que as instituições federais de ensino passaram nessa época, pelas propostas de reforma do Estado. Talvez tenha sido nesse cenário, em conjunto com a intensificação da pressão por publicação em periódicos científicos feita pelo sistema avaliativo, que se formou o amálgama avaliação-produtivismo. A composição dessa bricolagem tornou-se forte e intensificada ao longo dos anos. Muitas das questões levantadas nessa época mantêm-se atuais, mas outras discussões talvez não façam mais sentido para o contexto atual. Tomar tal união como naturalizada, sem atualização, não seria uma maneira de continuar reafirmando esse vínculo? A disseminação de que há produtivismo seria maneira estratégica para sua afirmação, longevidade, circulação, efetividade e manutenção de sua instituição? Seria uma possibilidade de linha de fratura forçar, torcer, romper com tal naturalização?

Quando aliamos divulgação do conhecimento e submissão à avaliação dos pares, à criatura do homo lattes, o que estamos fazendo? Respondemos, ao mesmo tempo, a dois regimes de forças diferentes: um que nos coloca dentro do sistema acoplado ao produtivismo e o movimenta, e outro que nos permite publicizar saberes e práticas que irão produzir efeitos, na promoção e movimentação do conhecimento. O estranhamento que se faz é: por que esses regimes fundem-se e se confundem, a ponto de não sabermos a quais deles estamos respondendo? Talvez seja nessa discrepância e, ao mesmo tempo, nessa acomodação mútua, que o par avaliação-produtivismo - estendido para o sistema avaliativo, em geral - gere tantas controvérsias.

Se somos subjetivados pela extração da verdade que nos é imposta, devemos buscar outros modos que rompam com tal movimento. Queremos afirmar com isso a necessidade de produzirmos novas indagações acerca de questões pertinentes à avaliação dos programas de pós-graduação, e de pensarmos se o vínculo avaliação-produtivismo ainda se faz atual; de que modo ele se atualiza; como podemos buscar novos sentidos para a questão da produtividade e da avaliação; como é possível não se reconhecer como pesquisador e docente agenciado exclusivamente por tal inscrição.

Atualmente, os sistemas de pós-graduação e de avaliação confundem-se, constam como componentes um do outro, suas linhas de tensão estão incrivelmente aproximadas e produzem efeitos sincronizados. O esforço de reajustes nesses sistemas acontece de maneira conjunta, e as exigências, tanto do coleta CAPES quanto da eficiência da pós-graduação, crescem em paralelo e consideravelmente. Em vista das suas intermediações, constantes atualizações e reordenamentos com novas inserções, inclusive das suas caducagens, entendemos que é possível operar a favor de resistências pontuais. Se quaisquer propostas de mudanças nos programas de pós-graduação devem passar pelo sistema de avaliação, o sentido inverso também ocorre. Não é só o sistema de avaliação que induz ações na pós-graduação, ela também agencia suas atualizações. Com isso, uma vez que o sistema de avaliação é uma tecnologia tão concreta e presente nos programas de pós-graduação, ações produzidas por este provocam ressonâncias e necessidade de reorganização naquele.

Portanto, apostamos nas práticas micropolíticas cotidianas, que possam bater o martelo e quebrar técnicas, estratégias e instrumentos e, ao mesmo tempo, que possam utilizar os engendramentos do sistema de avaliação como potência para a vida e para a produção de outros modos de existência. Apostamos em provocar o leitor, que tanto encontre brechas e possibilidades de escapar aos funcionamentos mais nocivos do sistema avaliativo quanto encontre nele mesmo modos de transformá-lo em outras potencialidades.

\section{Referências}

Alcadipiani, R. (2011). Resistir ao produtivismo: Uma ode à perturbação acadêmica. Cadernos EBAPE.BR, 9(4), 11741178. https://doi.org/10.1590/S1679-39512011000400015

Aragão, C. (2010). Conversa na Janela com o professor Francisco Portugal. Janelas: Boletim Eletrônico dos Alunos do 
Programa de Pós-Graduação em Psicologia, 5, 3-4.

Aragão, C., \& Cruz, A. C. (2010). O PPGP agora é nota 5 na avaliação CAPES. Janelas: Boletim Eletrônico dos Alunos do Programa de Pós-Graduação em Psicologia, 5(2).

Arantes, E. M. de M., Lobo, L. F., \& Fonseca, T. M. G. (2004). Pensar: a que será que se destina? Diferentes tempos de uma reflexão sobre a morte anunciada do educador. Psicologia \& Sociedade, 16(1), 50-68. https://doi.org/10.1590/S010271822004000100005

Axt, M. (2004). O pesquisador frente à avaliação na pós-graduação: em pauto novos modos de subjetivação. Psicologia \& Sociedade, 16(1), 69-85. https://doi.org/10.1590/S0102-71822004000100006

Barros, M. E. B. de. (2004). Não vale a pena economizar a vida para não gastar: notas introdutórias. Psicologia \& Sociedade, 16(1), Editorial do Número Especial.

Castro, L. R. de. (2010). Privatização, especialização e individualização: um outro mundo (acadêmico) é possível? Psicologia \& Sociedade, 22(3), 622-627. https://doi.org/10.1590/S0102-71822010000300023

Coimbra, C. M. (2004). Tensão ou oposição entre ciência e política na pós-graduação? Um falso problema? Psicologia \& Sociedade, 16(1),86-97. https://doi.org/10.1590/S0102-71822004000100007

Coordenação de Aperfeiçoamento de Pessoal de Nível Superior (CAPES). (2013). Documento de área 2013: Psicologia. Recuperado de: http://avaliacaotrienal2013.capes.gov.br/documento-de-area-e-comissao.

Deleuze, G. (1990). O que é um dispositivo? (W. F. do Nascimento, Trad.). Recuperado de: http://www.unb.br/fe/tef/filoesco/ foucault/art14.html.

Deleuze, G. (1992). Post-scriptum sobre as sociedades de controle (1972-1990). In Conversações (1ª ed., pp. 219-226, P. P. Pelbart, Trad.). Rio de Janeiro: Ed. 34.

Ferreira, A. A. L. (2011). Breves reflexões sobre o nosso sistema de pós-graduação: seus efeitos em nossas pesquisas e em nosso cotidiano universitário. Recuperado de: http:/intervox.nce.ufrj.br/hcte-sbhc-2011/contribui\%C3\%A7oes/ arthur_seminario.docx.

Foucault, M. (1997). Nascimento da biopolítica. In Resumo dos cursos do Collège de France 1970-1982 (pp. 87-97, A. Daher, Trad.). Rio de Janeiro: Jorge Zahar.

Foucault, M. (2005a). História da sexualidade I: A vontade de saber (M. T. da C. Albuquerque e J. A. G. Albuquerque, Trads). São Paulo: Graal. (Originalmente publicado em 1976)

Foucault, M. (2005b). Vigiar e punir: Nascimento da prisão (R. Ramalhete, Trad.). Petrópolis, RJ: Vozes. (Originalmente publicado em 1975)

Foucault, M. (2008). Segurança, território e população: curso dado no Collège de France 1977-1978. São Paulo: Martins Fontes.

Foucault, M. (2012). Na berlinda. In Segurança, penalidade e prisão / Michel Foucault. Coleção Ditos \& Escritos (Vol. 8, pp. 37-42, V. L. A. Ribeiro, Trad.). Rio de Janeiro: Forense Universitária. (Originalmente publicado em 1975)

Guedes, M. do C. (2011). Equívocos na publicação científica: algumas considerações. Psicologia USP, 22(2), 387-398. https://doi.org/10.1590/S0103-65642011000200006

Hutz, C. S., Rocha, M. L. da, Spink, M. J. P., \& Menandro, P. R. M. (2010). Perfil, avaliação e metas de produção intelectual dos programas de pós-graduação em psicologia. Psicologia: Reflexão e Crítica, 23(1), 25-34. https://doi.org/10.1590/ 


\section{$\underline{\mathrm{s} 0102-79722010000400004}$}

Kastrup, V. (2004). A aprendizagem da atenção na cognição inventiva. Psicologia \& Sociedade, 16(3), 7-16. https://doi.org/10.1590/S0102-71822004000300002

Kastrup, V. (2010). Pesquisar, formar, intervir [Texto]. In Associação Nacional de Pesquisa e Pós-Graduação em Psicologia (Org.), Anais do XIII Simpósio de Pesquisa e Intercâmbio Científico em Psicologia - Pesquisa em psicologia: formação, produção e intervenção (pp. 172-186). Fortaleza: ANPEPP.

Machado, L. D. (2004). O desafio ético da escrita. Psicologia \& Sociedade, 16(1), 146-150. https://doi.org/10.1590/S0102$\underline{71822004000100012}$

Mancebo, D. (2009). Trabalho docente: novos processos de trabalho e resistência coletiva [Texto]. Seminário para discussão de pesquisas e constituição de rede de pesquisadores: Associativismo e sindicalismo docente no Brasil. Rio de Janeiro.

Maraschin, C. (2004). Pesquisar e intervir. Psicologia \& Sociedade, 16(1), 98-107. https://doi.org/10.1590/S0102$\underline{71822004000100008}$

Maraschin, C., \& Sato, L. (2013). Recuperando leituras críticas sobre a avaliação na pós-graduação - dando continuidade à discussão e ao debate. Psicologia \& Sociedade, 25(1), 2-9. https://doi.org/10.1590/S0102-71822013000100002

Molon, S. I. (2004). Algumas questões epistemológicas e éticas da psicologia: a avaliação em discussão. Psicologia \& Sociedade, 16(1), 108-123. https://doi.org/10.1590/S0102-71822004000100009

Pozzana, L. (2010). Relato de evento: ANPEPP 2010. Janelas: Boletim Eletrônico dos Alunos do Programa de PósGraduação em Psicologia, 4, 2.

Rocha, M. L. da, \& Rocha, D. (2004). Produção de conhecimento, práticas mercantilistas e novos modos de subjetivação. Psicologia \& Sociedade, 16(1), 13-36. https://doi.org/10.1590/S0102-71822004000100003

Simões, R. H. S. (2004). Da avaliação da educação à educação da avaliação: o lugar do(a) educador(a) no processo da avaliação da pós-graduação no Brasil. Psicologia \& Sociedade, 16(1), 124-134. https://doi.org/10.1590/S0102$\underline{71822004000100010}$

Yamamoto, O. (2004). A avaliação dos programas de pós-graduação em psicologia. Temas em Psicologia, 12(1), 82-91.

Yamamoto, O. H., Tourinho, E. Z., Bastos, A. V. B., \& Menandro, P. R. M. (2012). Produção científica e "produtivismo": há alguma luz no final do túnel? RBPG, 9(18), 727-750. https://doi.org/10.21713/2358-2332.2012.v9.364

Zanella, A. V. (2004). Atividade criadora, produção de conhecimentos e formação de pesquisadores: algumas reflexões. Psicologia \& Sociedade, 16(1), 135-145. https://doi.org/10.1590/S0102-71822004000100011

\section{Endereço para correspondência}

Janaína Rodrigues Geraldini

End.: Av. Marechal Rondon, s/n - Jardim Rosa Elze. São Cristóvão/SE, CEP: 49100-000.

E-mail: jgeraldini@yahoo.com.br

Pedro Paulo Gastalho de Bicalho

End.: Av. Pasteur, 250 - Pavilhão Nilton Campos, Campus Praia Vermelha. Rio de Janeiro/RJ, CEP: 22290-240.

E-mail: ppbicalho@ufrj.br 